\title{
Asociación de Cooperativas Argentinas y Agricultores Federados Argentinos: dos buenos ejemplos de la transición en el cooperativismo agrario argentino
}

\author{
Graciela Mateo \\ Centro de Estudios de la Argentina Rural (CEAR) - Universidad Nacional de Quilmes (UNQ)
}

Resumen

Las cooperativas conforman una experiencia centenaria del agro argentino. En el siglo XXI, su desarrollo es uno de los principales ejes del Plan Estratégico Agroalimentario y Agroindustrial Participativo y Federal 2010-2020 para el logro de objetivos de competitividad y equidad social. Desde sus orígenes, el cooperativismo agrario procura cumplir con un doble objetivo: el primero, de carácter social, está destinado a la prestación de un servicio basado en principios de solidaridad, libre asociación y gestión democrática; el segundo, de carácter económico, está orientado a defender los intereses y mejorar la situación económica de sus asociados.

Desde un criterio funcional, las cooperativas agrarias pueden cubrir diversas actividades, necesidades o servicios, tales como el aprovisionamiento, la producción, comercialización, la transformación o industrialización y el crédito, cumpliendo una o varias de esas fases.

El artículo procura mostrar las transformaciones y permanencias operadas en el modelo cooperativo, a través del análisis de dos asociaciones emblemáticas del agro argentino: por un lado, la Asociación de Cooperativas Argentinas (ACA), primera entidad de segundo grado constituida en 1922 y que en la actualidad se encuentra entre los principales exportadores de cereales. Por otro, Agricultores Federados Argentinos (AFA), conformada en 1932 y que hoy es la principal cooperativa de primer grado del país.

Palabras clave

Cooperativismo agrario; Asociación de Cooperativas Argentinas; Agricultores Federados Argentinos

Códigos JEL: J54, Q13, R11, Z13

\author{
ASOCIACIÓN DE COOPERATIVAS ARGENTINAS Y AGRICULTORES \\ FEDERADOS ARGENTINOS: TWO GOOD EXAMPLES OF THE \\ TRANSITION IN THE ARGENTINE AGRARIAN COOPERATIVISM
}

\section{Abstract}

This paper analyzes the gestation of environmental protection regulations related to mining activities, as well as specific mining provisions that were approved and had an impact to reduce the negative effects to the natural environment.

The mining regulations that were approved in the Modern Age envisaged some measures in order to avoid damage to agriculture, livestock and to villages in the environment of mining activities.

In the XIX century, with a liberal State, several laws and mining regulations were slowly being adopted from the middle of the century, due to social conflicts, which introduced measures with health and natural protection effects. With a greater degree of state interventionism in the XX century, in a context of pressure from affected social groups, various sectoral rules for the protection of rivers and streams were approved. The Law of Mines in force introduced that it was approved by decree to fix the imperative conditions of protection of the environment, being the origin of the first Royal Decree of restoration of mining activities of 1982 .

Key Words

Agrarian Cooperativism; Asociación de Cooperativas Argentinas; Agricultores Federados Argentinos

JEL codes: J54, Q13, R11, Z13

Fecha de recepción del original: 15 de diciembre de 2018; versión definitiva: 16 de diciembre de 2019.

Graciela Mateo, Centro de Estudios de la Argentina Rural (CEAR) - Universidad Nacional de Quilmes (UNQ), Roque Sáenz Peña No 352 , Bernal (B1876BXD), Buenos Aires, Argentina.

Tlf.: (54 11) 4365 7100, interno 5744.E-mail: gracielamateoprieto@gmail.com; gmateo@unq.edu.ar .

ORCID ID: 0000-0003-3041-4813 


\title{
Asociación de Cooperativas Argentinas y Agricultores Federados Argentinos: dos buenos ejemplos de la transición en el cooperativismo agrario argentino
}

\author{
Graciela Mateo \\ Centro de Estudios de la Argentina Rural (CEAR) - Universidad Nacional de Quilmes (UNQ)
}

1. Introducción

La sociedad rural ha experimentado en el transcurso del siglo XX y en las primeras décadas del XXI importantes transformaciones, que han convivido, quizás más de lo que se cree, con significativas continuidades. Resulta entonces enriquecedor partir de un abordaje que haga foco en las transiciones. ¿Cómo puede definirse el término "transición"? En principio, puede decirse que es un cambio de estado por el que atraviesa una persona, objeto o hecho objetivo.

El poder de la transición no es ajeno al capitalismo y mucho menos a la historia argentina. La transición -expresa Hannah Arendt- es "un extraño período intermedio determinado por cosas que ya no son y por cosas que aún no han sido", y generalmente, en la Historia, esos intervalos, más de una vez mostraron poder" (citada en Girbal y Mateo, 2014). Las vías de la transición aparecen condicionadas por la cultura, las prácticas políticas y los factores socioeconómicos, que afectan las relaciones entre el Estado y la sociedad del complejo mundo rural.

En el agro, las transiciones se manifiestan, por ejemplo, en la ampliación de la frontera agrícola, la reconversión productiva de los sujetos para satisfacer las necesidades de los mercados internacionales. La modernización del campo incluye la organización de los agricultores en cooperativas agrícolas, uniones de crédito, así como en asociaciones de carácter reivindicativo, que han debido adaptarse, no sin conflictos, al modelo global que plantea el moderno agronegocio. Es así como la Argentina ha pasado de ser el granero del mundo a país sojero.

El escenario cooperativo rural también está en un proceso de cambio. Las cooperativas desarrollan nuevas actividades a nivel local con gran impacto, aprovechan las oportunidades coyunturales, las fortalezas y lecciones aprendidas en el camino recorrido desde los comienzos del cooperativismo agrario a fines del siglo XIX.
En tal sentido, innovación y desarrollo local se dan la mano a efectos de que el sistema cooperativo se acompase y aproveche las oportunidades que ofrece la tecnología y el conocimiento. Las cooperativas están en condiciones de lograr, a través del proceso asociativo (sexto principio cooperativo) escalas suficientes en el agronegocio para alcanzar los niveles de eficacia económica y de gestión, requeridos para mantener la competitividad de los productores, tanto socios como terceros no asociados.

En este contexto, el propósito de este artículo es evidenciar algunas de las transformaciones y de las permanencias operadas en el modelo cooperativo, a través del análisis de dos asociaciones emblemáticas del agro argentino: por un lado, la Asociación de Cooperativas Argentinas (ACA), primera entidad de segundo grado constituida en 1922 y que en la actualidad se encuentra entre los principales exportadores de cereales. Por otro, Agricultores Federados Argentinos (AFA), conformada en 1932 y que hoy es la principal cooperativa de primer grado del país.

2. Un breve recorrido por el cooperativismo agrario argentino

El accionar de las cooperativas agrarias, pieza clave de la economía social de primera generación, ha sido vital para la vida de los pueblos ya que se transforman en verdaderas herramientas al servicio del desarrollo endógeno. Poco a poco, las sociedades cooperativas se extienden hacia diferentes actividades y cubren buena parte de la geografía del país. Se constituye así un tejido de anclaje local, que posibilita la articulación flexible entre la descentralización de cada unidad productiva y de servicios y la fortaleza de la escala federativa. En efecto, en el transcurso de sesenta años, el cooperativismo agropecuario argentino pasa de la fundación de su primera sociedad a fines del siglo XIX' , a la instancia confederada, CO-

\footnotetext{
${ }^{1}$ En 1898 un grupo de colonos franceses fundan en Pigüé (provincia de Buenos Ai-
} 
NINAGRO, que a partir de 1956 reúne a miles de asociados en organizaciones de primero, segundo y tercer grado.

Con el correr del tiempo, la cooperativa agropecuaria se transforma en una empresa de empresas, que permite funcionar como grandes, a los productores chicos. A la inicial provisión de insumos, al acopio y comercialización de la producción y al crédito agrario, se suman una variada gama de servicios que la cooperativa le brinda al asociado: transformación/industrialización de las materias primas, divulgación de nuevas tecnologías, capacitación y logística. En este sentido, la organización cooperativa agropecuaria ha buscado avanzar en los eslabones de la cadena agroalimentaria para llegar lo más cerca posible del consumidor, hasta la transformación en un proveedor de alimentos (ver Mateo, 2012).

Sucesivos censos agropecuarios y relevamientos cooperativos confirman que, así como sucede desde sus orígenes, el movimiento cooperativo agropecuario argentino sigue integrado principalmente por pequeños y medianos productores de explotaciones caracterizadas por el trabajo familiar. Difundido en todas las regiones productivas del país, puede decirse de él, sin embargo, que es un fenómeno económico, social y cultural con predominancia en la pampa húmeda. Sin embargo, se evidencian islotes de organización cooperativa vinculados a la especialización productiva de ciertas regiones: en Cuyo y el Alto Valle del Río Negro, se organizan cooperativas frutihortícolas; en Mendoza, con expresiones parciales en otras provincias cuyanas y en el Noroeste, cooperativas vitivinícolas; yerbateras en Misiones y de modo marginal en Corrientes; algodoneras en Chaco y norte de Santa Fe; tabacaleras en varias provincias del NOA y del NEA.

El incremento del cooperativismo agrario en cuanto al número de empresas y socios si bien ha sido continuo no ha mantenido un ritmo regular. Mario Lattuada sostiene que desde mediados de la década de 1950, después de la gran expansión que tiene durante el peronismo histórico, el número de cooperativas agropecuarias tiende a estacionarse en una meseta hasta fines de los años '70. Desde el proceso de agriculturización y, más específicamente, a partir de la reforma financiera de 1977, comienzan las manifestaciones de la crisis del cooperativismo agropecuario (ver Lattuada, 2006).

Una serie de cambios macroeconómicos y sectoriales impactan en el accionar de estas empresas asociativas: 1) reducción de las pequeñas y medianas explotaciones, sustento del sistema comercial cooperativo; 2) aparición de nuevas formas de organización de la producción a través de los pools de siembra y fondos de inversión directa; 3) privatización y desregulación de puertos y actividades conexas, como los servicios de carga ferroviaria; 4) concentración y centralización del capital comercial en un reducido grupo de empresas, en su mayoría filiales de firmas multinacionales del agrocomercio; 5) aparición de cadenas de súper e hipermercados que desplazan a las cooperativas en el aprovisionamiento de la familia rural.

Frente a este panorama desaparecen numerosas entidades cooperativas, pudiéndose diferenciar dos etapas en este ciclo de decrecimiento y decadencia de organizaciones que

res) "El Progreso Agrícola" considerada la primera de las cooperativas agrarias que aún hoy subsiste. históricamente han sido capaces de establecer lazos sociales y económicos en los territorios donde se localizan. La primera, sobrevino en el inicio de la década de 1980 bajo los efectos de la reforma financiera. Las restricciones impuestas por la política crediticia llevan a que las cooperativas orientaran los excedentes acumulados al financiamiento de los socios. Los primeros signos de la crisis de las pequeñas y medianas explotaciones sumados a los costos del financiamiento derivan en dificultades de cobranza y enfrentamientos entre las entidades y sus asociados y de éstos entre sí. Muchos de ellos, sin capacidad para afrontar sus deudas con las cooperativas, desvían sus ventas hacia los circuitos privados de comercialización, mientras que sus cooperativas caen en una situación de insolvencia que afecta como en un círculo vicioso a otros productores y proveedores de su zona de influencia. Por otro lado, este endeudamiento acumulativo también se traslada a las entidades de segundo grado, poniendo en serias dificultades al sistema institucional en su conjunto.

El corolario de esta situación es previsible: cierre de gran cantidad de cooperativas primarias y de federaciones que como la Federación Argentina de Cooperativas Agropecuarias (FACA) -surgida en tiempos del peronismo, al amparo de la Federación Agraria Argentina- trasladan sus problemas a sus asociadas. Con inmovilizaciones crediticias crecientes, fruto de un endeudamiento acumulativo que ya excede el giro económico de estas organizaciones, superando en muchos casos el respaldo patrimonial disponible y amenazando con poner en serias dificultades a todo el complejo, los nobles y tradicionales principios cooperativos pierden consistencia frente a una realidad circundante cruda y divergente.

La segunda etapa de la crisis se da durante la década de 1990. La situación económico-financiera de las cooperativas agrarias, sobrevivientes a los severos cambios de la década anterior, condiciona, en buena medida, sus posibilidades empresariales. Muchas de estas empresas quiebran o se fusionan con otras entidades del mismo tipo ni bien se inicia el programa de convertibilidad. En otros casos, comienzan activos procesos de inversión y modernización tecnológica, especialmente en las instalaciones de acopio, empleando para ello financiamiento bancario, extendido a la cobertura de los pasivos generados por la venta anticipada de cereales y por los giros en descubierto de los años precedentes.

Las condiciones financieras prevalecientes en el momento en que se realizan las inversiones en nuevas tecnologías se modifican de manera brusca a partir de la llamada crisis del tequila en 1994 y aumenta de modo sustancial el costo financiero. Por su parte, los impactos del ajuste estructural impuesto por las políticas neoliberales de los '90 acrecientan las dificultades económicas y financieras de buena parte de los productores asociados, cuya capacidad de cancelación de las deudas con su cooperativa se ve seriamente afectada (ver Barbero, Gorenstein y Gutiérrez, 2000).

La experiencia de muchos países europeos ha demostrado que la disminución del número de cooperativas no siempre resulta un signo negativo para el movimiento. Un proceso de concentración en beneficio de un número reducido de cooperativas podría implicar un aumento del número de asociados $y$, de manera paralela, un avance significativo en el control del 
mercado por el movimiento cooperativo respecto de empresas de capital privado competidoras. Éste no ha sido el caso de la Argentina, donde a la disminución del número de entidades y socios se suma la drástica reducción de la participación cooperativa en el volumen de almacenamiento de granos, de su actividad en la faena de ganado y de su aporte relativo al total de las exportaciones agropecuarias del país.

Esta crisis va más allá de las consecuencias cuantitativas económicas y sociales, involucra cambios en sus estructuras organizativas y en los principios doctrinales fundacionales. Ante el nuevo contexto, las cooperativas emprenden una reconversión de su organización institucional y adoptan prácticas y discursos vinculados a la lógica empresarial que prioriza los criterios de rentabilidad económica sobre el principio cooperativo de la solidaridad (ver Lattuada y Renold, 2004).

El contexto económico de la década de 1990, caracterizado por un proceso de concentración y competitividad, desfavorece al pequeño y mediano productor, base societaria de las cooperativas agrarias, que registran entonces una reducción de sus asociados. Se generan entonces contradicciones entre los principios cooperativos y las prácticas institucionales, que provocan tres graves consecuencias para el cooperativismo agrario: pérdida de centralidad de la empresa cooperativa en los sistemas productivos locales; considerable reducción de los asociados y su pérdida de identidad cooperativa.

\section{Agronegocio, análisis y conceptualización}

En los años 60 comienza -de manera gradual y bajo los impulsos de las nuevas conductas tecnológicas- la agriculturización de la producción. La segunda posguerra - de la mano de EEUU- significa un quiebre en la instalación de este tema (ver Barsky y Gelman, 2001; Martínez Dougnac, 2013, 2016).

Progresiva y sostenidamente, la Argentina deja de ser "el granero del mundo" frente al avance de la soja, que desplaza de manera creciente no solo al trigo y al maíz, sino también a los cultivos intensivos agroindustriales. El algodón cultivado en la región del NEA -que sufriera en los años 60 la competencia de la fibra sintética- acusa el desplazamiento por la soja y la pobreza que se adueñan de la región y de sus actores, quienes durante largo tiempo fueran ocupantes precarios o intrusos en tierras fiscales. Se perfila un escenario de concentración y exclusión (ver Girbal-Blacha-Mateo, 2011).

En cuanto a la dinámica de ocupación del territorio con soja, se reconoce su despliegue desde la incipiente experiencia en Misiones. En los 70 se suma la provincia de Tucumán, hasta que en los años 80 se afianza, de la mano de los precios internacionales, un avance sojero en la región pampeana, en lo que se denomina, proceso de sojización.

Algunos autores han puntualizado que, a finales de estos años, se produce la expansión en el norte del país como parte de la pampeanización (ver Volante et al, 2006; Viglizzo y Jobbágy, 2010). El mayor crecimiento relativo en la superficie de soja sembrada ocurre durante el siglo XXI, en zonas hasta entonces consideradas marginales en la producción agraria. Estos resultados expresan un boom sojero, con un rol destacado de la siembra directa y la acción ideológica para su implantación de múltiples actores: académicos, mediáticos y políticos.

Se erigen entonces, los rasgos del modelo de producción del agronegocio, que se amplía a fines de la década de 2000 hacia otras regiones, como el Gran Chaco Argentino. Este modelo productivo rural que continúa vigente conlleva una destacada innovación tecnológica (biotecnología, maquinaria de alta productividad, siembra directa, herbicidas especiales, etc.), la inserción del sector financiero (siendo los mercados a futuro un emergente de dicha relación), actores productivos emergentes (pools de siembra que en su mayoría no son propietarios de las tierras que producen y se vinculan con el sector financiero), disponibilidad de sujetos productivos y sociales previos (productores, contratistas y la agroindustria que se fortalece como parte del modelo) y un Estado que dio el "visto bueno" para su instauración. En suma, el agronegocio desplaza de modo gradual a la agricultura como modo de territorialización y tiende, por lo tanto, a la sustitución del agricultor como sujeto social (ver Bolsi, 2008; Girbal-Blacha, 2014).

Se ha señalado el cambio entre la primera revolución verde de los años 70 -que implica una amplia incorporación de insumos y maquinaria-, de la de los 90 cuando se suman tecnologías de proceso ${ }^{2}$ y la consolidación del modelo de agricultura industrial.

En torno a la definición del agronegocio ha habido diferentes perspectivas. La Organización de las Naciones Unidas para la Alimentación y la Agricultura (FAO) define el término, surgido en la Universidad de Harvard (1957) "como la expansión de los negocios del sector agropecuario y rural y de sus cadenas, a partir de relaciones que involucran estructuras contractuales, alianzas o asociaciones ejecutadas principalmente por el sector privado a partir de los productores del sector agropecuario, sostenibles a largo plazo, que integran, además de un conjunto asociado de agricultores, a diversos agentes exógenos o de las cadenas agroindustriales y que podrían contar o no, con el apoyo de las políticas públicas" (ver Santacoloma, Suárez y Rivero, 2005).

Por otra parte, un representante de este modelo en Argentina, Héctor Ordóñez ${ }^{3}$, lo define -en su glosario de términos- como "una aproximación sistémica que delimita sistemas abiertos construidos verticalmente del campo al plato, incluyendo I+D, la industria de insumos, a los productores agropecuarios, a la agroindustria y al comercio minorista y exterior y

\footnotetext{
${ }^{2}$ La tecnología de procesos en términos generales "se conecta más con los aspectos no materiales del proceso de producción, que tienen que ver con la acumulación de conocimientos y experiencias en el manejo integral de todos los componentes, incluidos aquellos que provienen de la innovación integral" (ver Blanco, 2005).

${ }^{3}$ Ante la muerte de Héctor Ordóñez, el diario Clarín titula que fallecía el “Creador de los agronegocios" (Clarín, Buenos Aires, 8 de abril de 2006). Ordóñez fue uno de los impulsores del cambio de paradigma en las estrategias del negocio agropecuario en diversas instituciones públicas y privadas del país. Tuvo vínculos con la Asociación Argentina de Productores en Siembra Directa (AAPRESID), desde la dirección del Programa de Agronegocios y Alimentos de la Universidad de Buenos Aires (UBA). Además, participó junto a AAPRESID en el desarrollo de las Buenas Prácticas Agrícolas y su potencial certificación. Su formación profesional incluye los títulos de ingeniero agrónomo, psicólogo social y un Master en Negocios.
} 
los demás servicios anexos. El sistema agroalimentario aparece como un todo expresado en sistemas de valor que recorren la investigación, la producción, la transformación y la distribución" (ver Ordoñez, 2009).

Desde una perspectiva crítica -que involucra las consecuencias del modelo- se lo considera como una estructura de desarrollo agrario sostenido sobre crecientes inversiones de capital tras la persecución -a través de tecnología y más productividad-de mayores rentabilidades. Se reconoce que, como modelo, constituye una práctica discursiva y de legitimidad. Tiene un grado importante de "externalidad" con respecto al campo, influyen en la toma de decisiones sectores -que aparecen en las definiciones anteriores- que antes actuaban en otras esferas económicas (industria y banca).

En el plano de las consecuencias se pueden considerar: proceso de concentración económica, crisis social ${ }^{4}$, degradación de recursos naturales, perfiles nacionales monoproductores y dependientes -tanto tecnológica como económicamente-.

Bernardo Mançano Fernandes analiza para el caso brasileño que "la agricultura capitalista, en la nueva denominación agronegocio, se territorializa, expropiando al campesinado, promoviendo conflicto y desarrollo" (ver Mançano Fernandes, 2004).

Es significativo que desde sus primeros pasos hasta la actualidad la expansión del agronegocio mantenga condiciones favorables. A partir del gran ingreso de divisas que significa para el Estado (con las retenciones a las exportaciones) este modelo es sostenido por gobiernos de diferentes signos.

Dilma y Elder Andrade de Paula describen este fenómeno para Brasil -que responde, en un proceso histórico y social diferente, a una similar lógica del capital que la de su antecedente argentino- como "una forma de crear una especie de blindaje de ese modelo, intentando invisibilizar su conflictividad. El agronegocio intenta representar la imagen de la productividad, de la generación de riquezas para el país. De ese modo, aparece como espacio productivo por excelencia, cuya supremacía no puede ser desapropiada para la ocupación de la tierra" (ver Andrade de Paula, 2007). Por lo tanto, esta acción se hace posible debido a la construcción de un aparato ideológico de legitimidad sobre sus prácticas productivas. Los actores centrales son el capital financiero, los académicos -que aportan sus saberes técnicos y su legitimidad social- (múltiples universidades nacionales y organismos estatales de investigación ${ }^{5}$ ), las instituciones sectoriales -con práctica directa de sus lógicas- (entre ellas la Asociación Argentina de Producto-

\footnotetext{
${ }^{4}$ Este modelo hegemónico eclipsa y reniega de las formas de agricultura que no tengan sus lógicas productivas, como sucede con la agricultura familiar. En este sentido no solo los campesinos han sido amputados de la posibilidad de la reproducción de su forma de vida, sino que también -como ha confesado quien fuera presidente de la Federación Agraria Argentina, Eduardo Buzzi- ha sido el modelo de cultivo de Organismos Modificados Genéticamente (OMG) una gran trampa para los pequeños y medianos productores que entraron en dependencia con la multinacional Monsanto (ver Robin, 2008).

${ }^{5}$ Resulta relevante la presencia del mundo académico en el suplemento rural del diario Clarín. El Programa de Agronegocios y Alimentos (PAA) de la Facultad de Agronomía de la UBA (FAUBA) se crea en 1998, momento en el que se asienta el actua modelo del agronegocio.
}

res en Siembra Directa (AAPRESID ${ }^{6}$ y los sectores dirigentes que hacen viables estos modelos de acumulación.

\section{Asociación de Cooperativas Argentinas (ACA)}

El cooperativismo, en particular el rural, ha exhibido en el transcurso de su historia una tendencia hacia la adecuación a los cambios en las condiciones que definen los regímenes sociales de acumulación (RSA) ${ }^{7}$. Constituye pues un buen ejemplo para analizar las transiciones en el mundo agrario y la Asociación de Cooperativas Argentinas (ACA) se erige como un caso representativo. Fundada en la ciudad de Rosario el 16 de febrero de 1922, defiende los intereses de medianos productores agro ganaderos nucleados en 10 cooperativas primarias de las provincias de Córdoba y Santa Fe. Cumple con dos de las funciones básicas del cooperativismo agrario: aprovisionar de insumos al hombre de campo, desplazando al almacén de ramos generales, y asegurar y comercializar, en condiciones ventajosas, la producción de los asociados, liberándolos de los acopiadores y de empresas extranjeras como Bunge y Born y Dreyfus.

Para quebrar el individualismo del hombre de campo en 1924 se comienza a publicar el periódico La Cooperación, órgano de prensa de ACA que se mantiene hasta la actualidad. Su objetivo inicial es difundir los principios cooperativos y ayudar a los chacareros a desterrar el desconocimiento que tienen sobre cómo enfrentar los problemas que atentan contra su bienestar. Con celeridad se convierte en una importante y valiosa fuente, de valor documental, por sus actualizados artículos, las noticias nacionales e internacionales sobre las que pasa revista, y sus medulosos editoriales a través de los cuales la Asociación fija posición ante las diversas cuestiones de la realidad nacional.

A comienzos de los años 30, consciente de la necesidad de contar con infraestructura adecuada se embarca en la construcción de la primera red de elevadores de granos, brindando un nuevo servicio agropecuario. Superada la crisis en que la deja la suspensión de la garantía estatal para dicha construcción, en los años 40 ACA ingresa en la fase de industrialización de la producción de las cooperativas adheridas.

Si bien es innegable que la política económica del peronismo, en su primera fase, pone el énfasis en la expansión industrial, redistribuyendo a través del crédito la renta agraria,

\footnotetext{
${ }^{6}$ Se ha señalado la centralidad de AAPRESID -asociación que se asemeja a su antecesora estadounidense American Soybean Association, creada a comienzos del siglo $\mathrm{XX}$ - como herramienta de implantación de Monsanto en la región.

7 El RSA constituye un complejo proceso histórico recorrido por fuerzas contradictorias. El concepto no equivale al proceso de acumulación capitalista ni se corresponde con la noción clásica de modo de producción. Alude al conjunto de las instituciones y de las prácticas que inciden en el proceso de acumulación de capital, entendido este último como una actividad microeconómica de generación de ganancias y de toma de decisiones de inversión. Se suceden tres RSA en la Argentina moderna: agroexportador (1850-1930), sustitutivo de importaciones (1930-1990) y neolibera (1990-2001), cada uno con su particular incidencia en el sector agropecuario (ver Nun, 1987).
} 


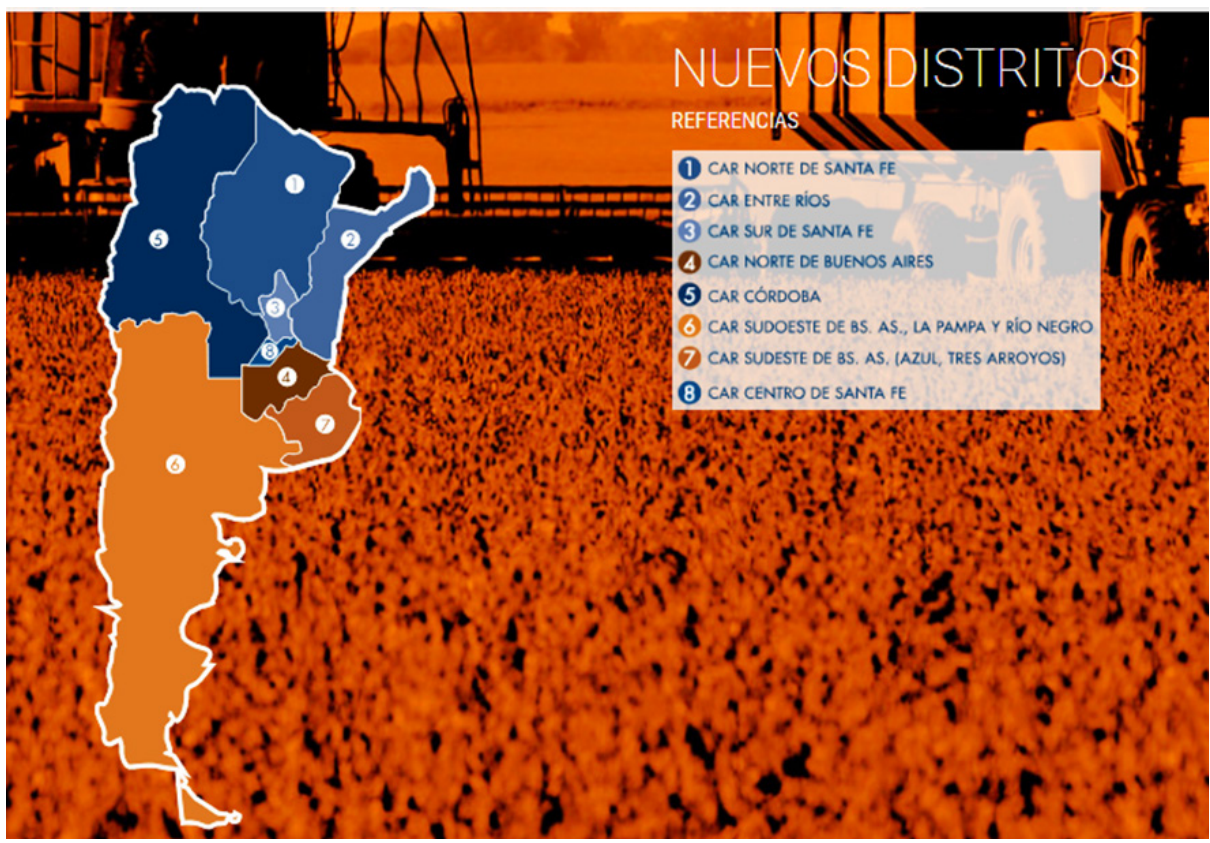

Fuente: http://www.acacoop.com.ar/quienes-somos.html

los sectores rurales no están exentos de la ayuda del Estado. Durante la vigencia del Primer Plan Quinquenal, la evolución económica y financiera de ACA es ponderada como "extraordinaria" por los mismos cooperativistas ${ }^{8}$, quienes, si bien aducen soportar el peso del financiamiento que el Estado hace de la pequeña y mediana empresa, se ven favorecidos por el crédito oficial. Al mismo tiempo, la Central cooperativa acrecienta en un $40,5 \%$ el número de entidades adheridas y en un $92,1 \%$ el de los cooperadores nucleados.

El volumen operado por ACA en el transcurso del ejercicio 1954/55 supera ampliamente los márgenes logrados en años anteriores. El mayor apoyo de las cooperativas asociadas permite superar en un $40 \%$ los valores comercializados en productos agrícolas; en el rubro hacienda se mantiene el ritmo de venta, a pesar de las dificultades existentes en el mercado para animales de alta cotización. Los frutos del país, en cambio, encuentran excelente colocación en los mercados nacionales, al igual que frutas, hortalizas y artículos de granja. La declinación observada en la exportación de productos responde a las características del comercio exterior, mientras que la importación registra incipientes progresos. Las ventas de productos industriales constituyen el fiel reflejo de la influencia de las nuevas fábricas que elaboran mayor cantidad de materia prima. La política de integración económica a la que está abocada la entidad, industrializando los productos de las cooperativas asociadas para su directa ubicación en los mercados consumidores, sumada a condiciones climáticas más favorables y a una política socio económica que privilegia la producción agropecuaria, permiten que ACA consolide su posición entre los he-

8 ACA, Memoria y balance general correspondiente al ejercicio 1950-1951, Buenos Aires, 1951, pp. 84 a 90. terogéneos actores del agro argentino, beneficiándose de las políticas del peronismo histórico (ver Mateo, 2005).

Luego de un breve período de intervención, en 1956 las cooperativas que integran la Central, mediante una acción conjunta recuperan su orden estatutario y designan, en una asamblea democrática, sus autoridades legítimas iniciándose una segunda etapa de consolidación y crecimiento que se extiende hasta fines de la década de 1970. Durante este período ACA registra un incremento de cooperativas adheridas, al tiempo que la institución reinicia la exportación directa de granos -que durante la administración peronista fuera monopolizada por el Instituto Argentino de Promoción del Intercambio (IAPI)-, realizando convenios de exportación granaria al Japón. Se inician las actividades industriales en la provincia de Córdoba, con la elaboración de aceites vegetales y subproductos en sus fábricas de Río Tercero y en Hernando.

A partir de la reforma financiera de 1977 y ante la suspensión por parte de la banca oficial del crédito de fomento agrario, las cooperativas tienen que asumir una función que no le es propia y para la que no están preparadas: el financiamiento de sus asociados. Las dificultades de los pequeños y medianos establecimientos agropecuarios se trasladan a las entidades cooperativas primarias a las que pertenecen, en un proceso que también impacta en la Central cooperativa, la que inicia una operatoria de financiamiento de las actividades de pre y pos cosechas y de apoyo crediticio a las cooperativas en problemas (ver Mateo, 2006).

Hoy ACA integra un verdadero grupo económico de capitales nacionales que adoptando estrategias innovadoras y ampliando sus prestaciones agropecuarias, se convierte en un centro generador de servicios que le permiten crecer y afianzarse como una empresa eficiente. Sin embargo, es posible 
percibir cierto grado de tensión entre el objetivo económico que la mueve, sus prácticas cotidianas y los principios cooperativos.

\section{Agricultores Federados Argentinos (AFA)}

Agricultores Federados Argentinos. Sociedad Cooperativa Limitada (AFA SCL) se funda el 3 de noviembre de 1932 como una entidad cooperativa de consumo, provisión, crédito, transformación y comercialización, en tiempos del Estado interventor y los subsidios a la producción agraria. La intención de Esteban Piacenza, presidente de la Federación Agraria Argentina (FAA), es constituir una cooperativa de orden dependiente y de administración centralizada -con sede en la ciudad de Rosario- integrada por agencias solidarias (centros cooperativos primarios) que convergieran en los puertos de embarque para evitar a los intermediarios de la comercialización?.

Desde las páginas de La Tierra, órgano de prensa de la Federación, se divulgan las bondades del cooperativismo para prescindir por completo de los almacenes de campaña -en lo referente al acopio y venta- y como medio para implantar establecimientos para la elaboración de los productos agrarios. En este sentido, la acción cooperativa se plantea como parte de las prácticas gremiales de la FAA y su estrecha relación-que la diferencia de aquellas entidades nucleadas en torno a ACAqueda inscripta en el artículo 11 de los Estatutos Sociales aprobados por unanimidad en 1932: "podrá pertenecer a la sociedad toda persona (varón o mujer) que acepte los presentes estatutos y los reglamentos internos de la sociedad, que pertenezca al gremio agrario, que sea socio de la Federación Agraria Argentina y que tenga más de dieciocho años de edad"10.

La creación de AFA también puede considerarse una estrategia jurídica de la Federación que, en tiempos de crisis del modelo agroexportador y de la entidad madre, intenta salvaguardar la representación de sus socios, el capital comprometido y el diario La Tierra.

Esteban Piacenza asume la presidencia conjunta de AFA y de la FAA, situación que no dura más de un año. El resto de los integrantes del primer Directorio también poseen experiencia gremial y cooperativa. La misión institucional que AFA propone es: "servir cada vez mejor a las familias productoras

\footnotetext{
${ }^{9}$ Característica que la distingue de otras cooperativas de primer grado, asimilándola con las de segundo grado: la misma Asociación de Cooperativas Argentinas (ACA), SanCor Cooperativas Unidas Limitadas, por ejemplo.

10 En singular oposición al artículo 11 de la primera Ley de Sociedades cooperativas 11.388/26 que expresa que: "(Las cooperativas) No podrán tener por fin principal ni accesorio la propaganda de ideas políticas, religiosas, de nacionalidades o regiones determinadas; ni imponer como condición de admisión la vinculación de los socios con organizaciones religiosas, ni partidos políticos o agrupaciones de nacionalidades o regional' (cursivas añadidas). Los Estatutos Sociales vigentes desde su reforma en 1995 establecen en el Capítulo II, art. 9: “Podrán asociarse a esta Cooperativa las personas de existencia visible o ideal que revistan la calidad de productores agropecuarios, que acepten expresamente el presente Estatuto y los reglamentos que en su consecuencia se dicten y que no tengan intereses contrarios a la misma. Los menores de 18 años de edad y las mujeres casadas podrán asociarse sin necesidad de autorización de quien ejerza la patria potestad y disponer de su haber en ella por sí solos..." Estatutos, pp.10-11.
}

asociadas a través de la defensa del valor de su producción, promoviendo la diversificación y valor agregado de la misma, por medio de una gestión transparente y brindando las herramientas necesarias para que mejoren su calidad de vida y participen activamente en el desarrollo de sus comunidades"11.

A un año de su fundación, la entidad cuenta con más de 2.000 asociados. Hasta 1950, su estructura administrativa difiere de la actual y su área de influencia abarca gran parte de las provincias de Santa Fe, Córdoba y Buenos Aires, además de una porción considerable de la provincia de Entre Ríos. Antes de la creación de las Agencias (hoy Centros Cooperativos Primarios, CCP) actúa en las localidades a través de agentes de colocación de la producción, quienes canalizan la operatoria por medio de la Administración Central de Rosario o por la Delegación Buenos Aires.

A partir de 1947, cuando el Estado peronista mantiene sus distancias discursivas con el cooperativismo, se inicia una etapa de consolidación institucional con la creación de las Agencias (hoy CCP) con Sub-Consejos Consultivos (hoy denominados Consejos Asesores Locales) y personal permanente. Su expansión durante estos años es significativa, construyendo elevadores, silos, depósitos de almacenamiento y galpones en diversas áreas. El constante crecimiento del número de socios de AFA motiva la creación por parte de la FAA de una entidad de segundo grado: la Federación Argentina de Cooperativas Agropecuarias (FACA). El propósito de la entidad madre es construir un "cooperativismo integral" que reemplace al antiguo sistema de comercialización, inscribiendo el accionar cooperativo en el contexto de la lucha gremial" (ver Mateo y Olivera, 2006).

En la actualidad los 36.000 productores asociados cuentan con una estructura compuesta por más de 1.600 empleados permanentes en 26 Centros Cooperativos Primarios, que sumados a los 65 Sub-Centros, 42 Oficinas y 9 Representaciones permiten que la entidad tenga presencia arraigada en 142 localidades de 9 provincias argentinas: Santa Fe, Buenos Aires, Córdoba, Entre Ríos, Santiago del Estero, Chaco, Salta, Tucumán y San Luis. La actividad principal de esta cooperativa continúa siendo el acopio y la comercialización de granos y oleaginosas cuyo elevado volumen permite trasladar un mejor precio a sus socios. Entre los servicios que hoy presta se encuentran la provisión de agro insumos, la comercialización directa de hacienda y productos especiales, transporte de granos y sub-productos, muestras técnicas y ensayos a campo, expendio de combustibles y exportación directa.

Según el último ranking publicado por el Monitor Cooperativo Mundial, realizado por la Alianza Cooperativa Internacional y el Instituto Europeo de Investigación sobre Empresas Cooperativas y Sociales, AFA es la cooperativa más grande de Argentina, la número 102 en el mundo y ocupa el 31 lugar en tanto cooperativa agropecuaria. Por su parte, El Monitor $2018^{12}$ certifica a AFA SCL como una de las cooperativas líde-

\footnotetext{
11 Página web AFA: http://www.afascl.com/.

12 El de 2018 es el séptimo en publicarse, lleva por título“Exploración de la Economía Cooperativa" y ha sido coordinado por dos reconocidos especialistas de la investigación del movimiento cooperativo mundial: el alemán Bruno Roelans y el italiano Gianluca Salvatori, lo cual le otorga al documento una legitimidad académica incues-
} 
res, no solo en historia y trayectoria, sino en cuanto a su potencial económico y social, posicionándola como un referente indiscutido dentro del movimiento cooperativo argentino y latinoamericano ${ }^{13}$.

6. Continuidades y cambios ante el agronegocio

El análisis de ambas cooperativas se hace a partir de tres ejes transversales. Sin embargo, estos focos de estudio no se pueden tomar como senderos aislados, sino como un entramado. Ambas entidades se analizan por separado para potenciar el ejercicio comparativo (ver Bageneta y Mateo, 2015).

\subsection{Eje: Intervención territorial}

En esta sección se considera la acción que adopta cada cooperativa en relación a su presencia en un territorio, donde el agronegocio se torna hegemónico.

Cientos de investigadores reinterpretan en la última década en toda América Latina los aportes que hiciera el geógrafo Milton Santos no solo en torno al polisémico concepto de territorio, sino a la reconstrucción de la teoría social crítica ${ }^{14}$. Otro geógrafo brasileño, Carlos Walter Porto Gonçalves (2008), concibe al territorio como un espacio de gobernanza, apropiado, instituido por sujetos y grupos que se afirman a través de él; en tanto Bernardo Mançano Fernandes (2009), considera que existen múltiples territorios según las acciones para controlar el espacio. Cada institución, organización, sujeto construye su propio territorio y el contenido de su concepto y poder político para mantenerlo.

La definición del geógrafo argentino, Horacio Bozzano, discípulo de Santos, parecería complementar las precedentes. El territorio es, en primera instancia, una construcción socialnatural cooperativa y conflictiva; y en segunda instancia, es un lugar de variada escala -micro, meso, macro- donde actores -públicos, privados, ciudadanos, otros- ponen en marcha procesos complejos de interacción -complementaria, contradictoria, conflictiva, cooperativa- entre sistemas de acciones y sistemas de objetos, constituidos éstos por un sinnúmero de técnicas -híbridos naturales y artificiales- e identificables

tionable.

13 "AFA SCL la cooperativa más grande del país según un ranking mundial” en El Litoral, 04/1272018. Disponible en: https://www.ellitoral.com/index.php/id um/185215 afa-scl-la-cooperativa-mas-grande-del-pais-segun-un-ranking-mundial-actualidadcampolitoral.html.

${ }^{14}$ La naturaleza del espacio. Técnica y tiempo. Razón y emoción, obra interdisciplinar que ofrece un tratamiento pionero entre la técnica y el espacio y entre el espacio y el tiempo, bases para la construcción de un sistema de conceptos coherentemente formulado, con el objeto de definir el espacio geográfico y su papel activo en la dinámica social. según instancias de un proceso de organización territorial en particulares acontecimientos -en tiempo-espacio- y con diversos grados de inserción en la relación local-meso-global. El territorio se redefine siempre (ver Bozzano, 2017).

\subsubsection{ACA}

ACA es la primera cooperativa agropecuaria de segundo grado del país y de América. Hoy el sistema cooperativo ACA está formado por 150 cooperativas primarias que agrupan a 50.000 productores y consolidan una parte fundamental de la cadena agroindustrial de la Argentina. Esta cooperativa de cooperativas con sucursales y filiales en las ciudades de Rosario, Bahía Blanca, Córdoba, Tres Arroyos, Necochea, Pergamino, Santa Fe, General Pico y Paraná, está presente en más de 600 localidades distribuidas en las provincias de Buenos Aires, Córdoba, Chaco, Entre Ríos, La Pampa, Río Negro, Santa Fe y Santiago del Estero. A su vez esta entidad de segundo grado integra la Confederación Intercooperativa Agropecuaria Coop. Ltda. (CONINAGRO).

Para que la cobertura territorial sea más eficiente y directa se crean los Consejos Asesores Regionales (CAR) constituidos por las cooperativas radicadas por zona. Sus funciones y atribuciones son: 1) asesorar a la Central en todos los asuntos y problemas de la zona donde se encuentran ubicadas las cooperativas de base que integran cada $C A R$, relacionados con la producción e industrialización de los productos de la región. 2) Hacerle llegar sugerencias de carácter general. 3) Colaborar en el Consejo de Administración de la entidad en las funciones que éste les encomiende. En la actualidad hay ocho Consejos Asesores Regionales: 1) CAR Norte de Santa Fe, CAR Centro de Santa Fe, CAR Sur de Santa Fe, CAR Entre Ríos, CAR Norte de Buenos Aires, CAR Sudeste de Buenos Aires, CAR Sudoeste de Buenos Aires, La Pampa y Río Negro y CAR Córdoba. Como puede apreciarse la presencia cooperativa en la zona núcleo de la pampa húmeda, constituye un pilar fundamental del sistema cooperativo ACA. No obstante, algunas de sus cooperativas asociadas, como es el caso de la Unión Agrícola de Avellaneda ubicada en la provincia de Santa Fe, ha ampliado su inserción territorial hacia áreas linderas de provincias limítrofes como Corrientes, Chaco, Formosa y Santiago del Estero.

\subsubsection{AFA}

Esta cooperativa con sus 26 centros cooperativos primarios (CCP), puede asimilarse a una entidad de segundo grado, pero sus estatutos indican que es una cooperativa primaria. La mayoría de esos CCP se fundan en el sur santafecino, en el 


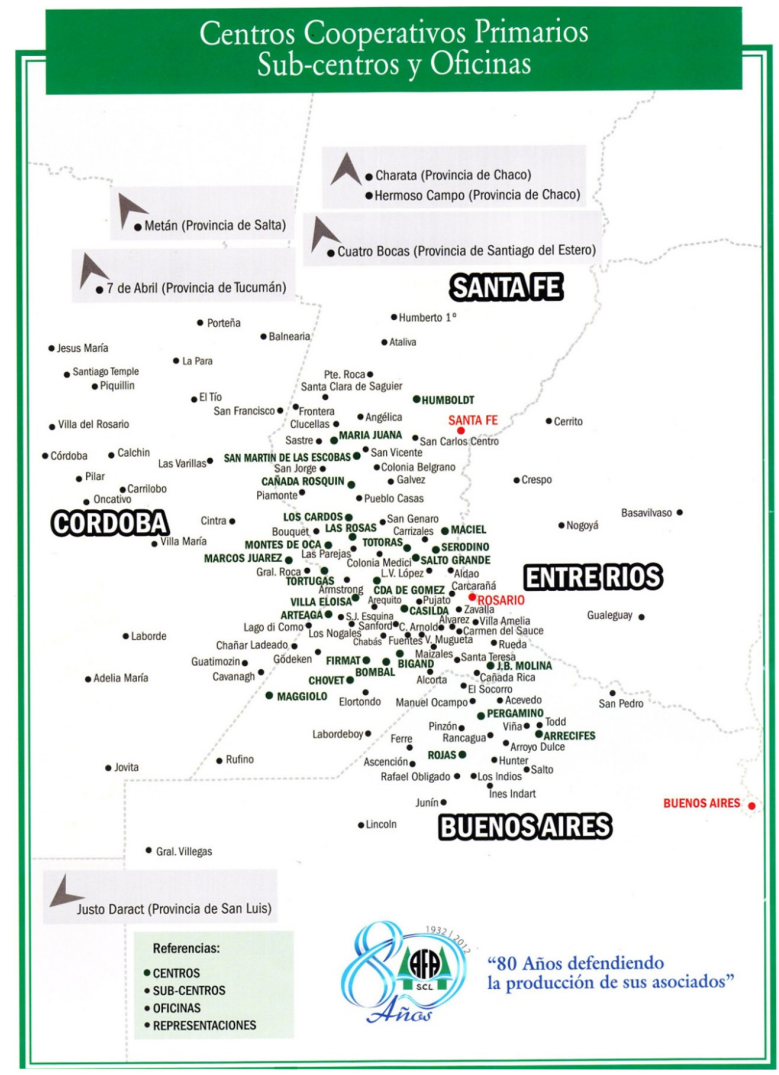

Fuente: http://afa.afascl.coop/revista-agricultores.php

norte de la provincia de Buenos Aires (Pergamino, Rojas y Arrecifes) y en la localidad cordobesa de Marcos Juárez durante las décadas de 1950 y 1960. Otros dos (Cañada Rosquín y Montes de Oca), ambos en Santa Fe, se constituyen en la década de 1970 y los últimos, también en territorio santafesino, son Chovet en 1984 y Serodino en 1991. Su expansión, concentrada en la región pampeana, la ha convertido en uno de los más fuertes comercializadores de granos. De estos CCP dependen 65 Sub-Centros, 42 oficinas y 9 Representaciones, ubicados mayoritariamente en el sur de Santa Fe, noroeste bonaerense y en el oeste de la provincia de Córdoba, que le suministran una densidad logística difícil de igualar por otras empresas. Pero en los últimos años AFA avanza más allá de la zona núcleo de la región pampeana, llega a algunas provincias del NOA, NEA y Cuyo, que se suman a la expansión alcanzada en la vecina provincia de Entre Ríos. El CCP Maciel de Santa Fe mantiene presencia territorial a través de dos subcentros en Metán (Salta) y 7 de abril (Tucumán) y la oficina de Cuatro Bocas (Santiago del Estero). Por su parte el CCP Cañada Rosquín cuenta con un subcentro en Charata (Chaco); en tanto Firmat ha prolongado su presencia física en Justo Daract (San Luis) ${ }^{15}$.

\footnotetext{
15 AFA. Balance Social Cooperativo, n॰ 8, ejercicio 2011/2012, p. 9.
}

El mapa evidencia que más allá de la reciente expansión hacia localidades del noroeste, noreste y de San Luis, la cooperativa mantiene, al igual que su gran competidora, ACA, su entramado territorial en la región pampeana.

\section{Eje: Estructura de negocios}

A partir de este eje de análisis se busca dar cuenta de los cambios que experimentan las cooperativas, objeto de estudio. Uno de los elementos que permite a ambas cooperativas mantener una relación sinérgica con el modelo del agronegocio es su estructura de "negocios", o sea, las producciones que reciben y las prestaciones que brindan. 


\subsection{ACA}

Para dar sustento a una cada vez más consolidada estructura comercial ACA ha organizado 46 Centros de Desarrollo Cooperativo que son unidades operativas para la atención de los productores agropecuarios, sean socios o terceros no asociados. Su finalidad es complementar el tonelaje originado a través de las entidades primarias y así posibilitar el accionar cooperativo en la mayor parte del territorio del país. En estos centros se prestan, entre otros, servicios de acopio de cereales y oleaginosas, distribución de insumos agropecuarios y asesoramiento en materia agraria.

ACA es uno de los más importantes operadores de granos del país, con una participación del 17\% del mercado total, equivalente a 19.800.000 millones de toneladas anuales entre cereales, oleaginosas, legumbres y miel.

La comercialización de productos agrícolas es su principal actividad y ofrece a las cooperativas y productores opciones para la venta de sus granos, destinados a molinos, fábricas de aceite, diversas industrias y para la exportación.

La recepción, acondicionamiento y transporte de los granos originados constituyen una pieza fundamental en la cadena de valor agroindustrial. ACA, sus 150 cooperativas de base distribuidas en 8 Consejos Asesores Regionales (CAR) y sus 46 Centros de Desarrollo Cooperativo (CDO) configuran un mecanismo de logística que apunta a satisfacer las necesidades surgidas desde la comercialización interna o externa.

Si bien la base de su infraestructura se localiza en la región pampeana, ACA ha construido una planta de almacenaje en Selva, al sur de la provincia de Santiago del Estero.

Pionera en la construcción de instalaciones portuarias y elevadores de granos, cuenta con dos puertos ubicados en San Lorenzo (provincia de Santa Fe) y Quequén. El primero situado sobre la margen derecha del río Paraná, forma parte del importante complejo que tiene un sustancial desarrollo a partir de la década de 1980 en la zona de Rosario y Gran Rosario. Su evolución anual supera las 3.000.000 de toneladas y opera con cereales y fertilizantes sólidos y líquidos. El puerto Quequén, estación marítima natural de aguas profundas con rápida salida al mar, ubicado en la provincia de Buenos Aires, ronda una evolución anual cercana a las 2.500 .000 de toneladas. En Chaco posee puerto Vilelas utilizado para la carga de barcazas con una evolución anual de 200.000 toneladas. Se suma un puerto en construcción en la localidad santafecina de Timbúes ${ }^{16}$.

La Asociación accede con sus productos a más de 40 países en forma directa, sin ningún tipo de intermediación. Exporta cereales a China, Japón, India, los países árabes y Cuba, así como también semillas, de semilleros propios, a Paraguay, Uruguay y Brasil.

Un informe de la firma Zeni en base a datos oficiales revela que ACA se ha posicionado en el décimo lugar dentro de los diez principales exportadores de granos, subproductos

\footnotetext{
16 Página web de ACA: http://www.acacoop.com.ar/index.html.
}

y aceites de Argentina en 2016, con una venta al exterior de 3.474.991 toneladas ${ }^{17}$.

Para las cooperativas resulta estratégica la exportación, ya que es un segmento clave de la economía, siendo el eslabón de mayor rentabilidad y control en la cadena, que hasta ahora es dominada por empresas extranjeras (ver Fontenla, 2016).

El 35\% de los cereales y oleaginosas originados en ACA se exportan, principalmente a través de los puertos San Lorenzo y Quequén, puertos equipados con la más alta tecnología.

A fines de 2012 se realiza la botadura de la primera barcaza propia "ACA 1", con una capacidad de 2.800 toneladas. Este sistema de cargas permite optimizar costos de logística por el uso de la hidrovía.

Para garantizar los estándares de calidad exigidos por los clientes internacionales y la inocuidad de los productos embarcados, el Departamento de Comercio Exterior de ACA ha desarrollado Programas de Trazabilidad y Procesos de Identidad Preservada, a efectos de atender la demanda de cereales y semillas oleaginosas de calidad diferenciada.

Para abonar el perfil asociativo de ACA y en virtud del sexto principio cooperativo pueden mencionarse las alianzas establecidas con cooperativas de otros países, como el joint venture cooperativo Zen Noh ACA Limited, radicado en Hong Kong e integrado por ACA y por la National Federation of Agricultural Co Cooperative Associations de Japón desde 1964. A partir de la creciente demanda del mercado del sudeste asiático, especialmente de China, su filiación continúa vigente. Zen-Noh es una federación de cooperativas que nuclea a 720 entidades primarias que, en conjunto, congregan a 5.000 .000 de productores asociados. Su objetivo es atender las necesidades de los usuarios finales de esa región e impulsar este mercado con cereales y oleaginosas, como maíz, poroto de soja, sorgo, cebada cervecera y harina de soja. En este marco, el convenio anual de cooperación $N^{\circ} 51$ establece la provisión de 400.000 toneladas de dichos productos. Su participación es más del 30\% del total de la producción de alimentos balanceados de Japón y factura más de 55 mil millones de euros anuales. Por su parte, en el ámbito del Mercosur, ACA ha suscripto un convenio con la Federación de Cooperativas de Producción del Paraguay (FECOPROD), entidad que agrupa a 33 cooperativas que representan el $60 \%$ de la producción agropecuaria de dicho país. El objetivo del acuerdo es la identificación de áreas potenciales para el intercambio comercial de productos elaborados y de conocimientos técnicos entre ambas instituciones y sus cooperativas afiliadas para el desarrollo de infraestructura logística y actividades productivas. Asimismo, dos empresas de apoyo a la exportación en el exterior son Fisway S.A. y KesiTradong Limited, cuyos capitales accionarios pertenecen en su totalidad a ACA. La primera está radicada en la República Oriental del Uruguay y la segunda en Hong Kong (ver Fontenla, 2015).

Las siguientes son algunas de las áreas que presenta ACA en términos operativos y organizacionales para la elaboración y distribución de insumos necesarios para la cadena agroindustrial:

\footnotetext{
17 "El top ten de los exportadores de granos: los ganadores en 2016", La Nación, 14/02/2017. Disponible en https://www.lanacion.com.ar/1984476-el-top-ten-de-losexportadores-de-granos-los-ganadores-en-2016.
} 
Cuadro 1. Productos agrícolas y productos elaborados comercializados, Asociación de Cooperativas Argentinas, $2012-2017$

\begin{tabular}{|c|c|c|c|c|c|}
\hline \multirow{2}{*}{ Productos } & \multicolumn{5}{|c|}{ Ejercicios (en kilogramos) } \\
\hline & $2012 / 13$ & 2013/14 & 2014/15 & $2015 / 16$ & 2016/17 \\
\hline Productos Agrícolas & 13.404 .628 .626 & 13.918 .443 .745 & 18.275.670.096 & 17.876 .594 .669 & 19.803 .845 .908 \\
\hline 1. Cereales & 6.932 .587 .583 & 5.045 .144 .710 & 7.465.633.149 & 7.543.337.904 & 9.820 .447 .657 \\
\hline - Alpiste & 38.050 & - & - & - & - \\
\hline - Arroz & 1.276 .490 & 2.126 .678 & 323.565 & 608.574 & 2.883 .545 \\
\hline - Avena & 1.836 .930 & 1.351 .524 & 915.236 & 1.541 .710 & - \\
\hline - Cebada & 639.540 .099 & 836.385 .726 & 675.361 .829 & 931.470 .626 & 648.742 .867 \\
\hline - Colza & 72.681 .387 & 52.167 .357 & 21.062 .269 & 23.630 .777 & 8.771 .620 \\
\hline - Maíz & 3.434.703.279 & 2.527.346.564 & 3.936.207.039 & 3.845.897.625 & 4.436 .891 .361 \\
\hline - Mijo & 221.163 & 404.285 & - & - & - \\
\hline - Sorgo & 954.754 .761 & 345.197 .249 & 424.894 .182 & 178.071 .834 & 243.395 .438 \\
\hline - Trigo & 1.815 .584 .489 & 1.261 .811 .812 & 2.377 .844 .736 & 2.521.210.863 & 4.451 .621 .046 \\
\hline -Varios & 11.950 .935 & 18.353 .515 & 29.024 .293 & 40.905 .895 & 28.141 .780 \\
\hline 2. Oleaginosos & 6.472 .041 .043 & 8.873.299.035 & 10.810.036.947 & 10.333.256.765 & 9.983.398.251 \\
\hline - Girasol & 495.425 .049 & 449.815 .176 & 428.667 .879 & 539.665 .883 & 611.229 .554 \\
\hline - Lino & 1.454 .309 & 1.569 .693 & 818.447 & 2.617 .387 & 3.228 .979 \\
\hline - Maní & 38.899 .170 & 32.140 .980 & 16.669 .920 & 73.781 .560 & 42.444 .110 \\
\hline - Soja & 5.936.262.515 & 8.389.773.186 & 10.363.880.701 & 9.717.191.935 & 9.326 .495 .608 \\
\hline Productos elaborados & 349.447 .215 & 285.990 .578 & 386.422 .640 & 327.982 .830 & 374.390 .735 \\
\hline Aceites & 65.306 .364 & 54.626 .000 & 70.962 .500 & 69.801 .000 & 71.705 .000 \\
\hline Subproductos & 284.140 .851 & 231.364 .578 & 315.460 .140 & 258.181 .830 & 302.685 .735 \\
\hline Totales & 13.754.075.841 & 14.204 .434 .323 & 18.662.092.736 & 18.204.577.499 & 20.178 .236 .643 \\
\hline
\end{tabular}

Fuente: Asociación de Cooperativas Argentinas, Memoria y Balance correspondiente al ejercicio 2016-2017, Buenos Aires, 2017 , p. 21.

Semillas. Evidencian un crecimiento significativo en el mercado a partir de híbridos destacados de girasol, maíz y sorgo granífero y forrajero, así como también variedades de soja y trigo. ACA cuenta con dos criaderos de semillas propios ubicados en la provincia de Buenos Aires: uno enfocado en granos finos, fundamentalmente trigo, y otro destinado a semillas híbridas, donde, además, funcionan dos plantas de procesamiento y logística. Posee un campo propio en la provincia de San Luis, destinado a la producción de sus semillas, donde se aplica tecnología de punta tanto en lo que respecta a riego como a fertilización por ambientes en busca de maximizar los recursos empleados. Asimismo, en la ciudad de Pergamino (provincia de Buenos Aires) cuenta con un Laboratorio Biotecnológico para fortalecer la investigación en esta área que apunta a acortar los tiempos de mejoramiento genético y lograr una mayor precisión en las técnicas de selección. Se constituye así una red de laboratorios que realiza servicios de diagnóstico de fertilidad y asesoramiento al productor.

Insumos Agroveterinarios. Otro de los servicios, propio del agronegocio, es la variedad de productos para la nutrición y sanidad animal que ACA vende al productor rural. En su planta farmacobiológica de Campana (Buenos Aires) produce una línea de productos veterinarios que incluye antiparasitarios, antibacterianos, minerales inyectables, biológicos y hormonales, y otros fármacos que posibilitan la prevención, el control y el tratamiento de las enfermedades existentes en las diferentes geografías y modelos productivos ganaderos de nuestro país, como por ejemplo la vacuna antiaftosa. En la planta de San Nicolás (Buenos Aires), se elaboran productos destinados a la nutrición animal bovina, de cerdos, peces y mascotas.

Fertilizantes. ACA constituye una de las principales empresas argentinas dedicadas a la producción, importación y distribución de fertilizantes agrícolas. El Superfosfato Simple GS $A C A$, producido en la localidad de Ramallo, es considerado clave para la reposición de nutrientes en soja. Asimismo, gracias a su sistema de distribución, único en el mercado, consigue llevar al productor toda la línea de productos destinados a la nutrición de cultivos. La Asociación ha fortalecido su posicionamiento estratégico en el mercado de fertilizantes líquidos a través de la línea de productos $S O L-$ $M I X$, producidos en la localidad de Campana. El segmento de herbicidas Glifosatos representa el 52\% de las ventas totales para el ejercicio 2016-2017. Una evidencia más de la importancia de la soja en la estructura de negocios de ACA, en la que, como se ve en el Cuadro 1, la comercialización de esta oleaginosa supera a cereales como el trigo y el maíz. 
Silo-bolsa. Fabricados con tecnología de última generación, en el establecimiento que la empresa posee en General Pico (provincia La Pampa), con la marca PentasiloACA. La capacidad de producción es de 75.000 unidades por año. Es la sexta planta que funciona en el país dentro de ese rubro.

Con el objetivo de fomentar la diversificación de cultivos entre los productores asociados, ACA también exporta arvejas. Los principales destinos son India, Arabia Saudita, Italia, Estonia y Senegal. La recesión de Brasil, principal destino de este producto en las exportaciones argentinas, impacta de forma negativa en el volumen exportado, que en el ejercicio 2016-2017 se ha reducido en un $64 \%$ con respecto al ejercicio anterior.

Por otra parte, ACA constituye actualmente el principal exportador de miel de la Argentina. De acuerdo con la información provista por su página institucional, toda su operatoria se realiza desde la planta ubicada en Pilar (provincia de Buenos Aires), cuya producción está sometida a múltiples certificaciones, entre ellas las normas ISO. Allí se dispone de un sistema automatizado de última generación para descarga, calado, pesaje y limpieza de tambores, y de un laboratorio de análisis de última generación y una planta de homogeneización y tratamiento de efluentes. La miel llega a quince mercados, exportándose a distribuidores y envasadores de Alemania, Inglaterra, Irlanda, Francia, Italia, España, Bélgica, Dinamarca, Suecia, Estados Unidos, Canadá, Turquía, Arabia Saudita y Japón, entre otros. En el año 2000, ACA alcanza su récord de comercialización de miel al exportar 24.100 toneladas, cifra que representa una participación en la exportación nacional de dicho producto del $26,9 \%$, posicionándose, así, como el mayor exportador del mundo en términos de volumen. Durante el ejercicio 20162017 se han embarcado 6.991 toneladas con destino a Estados Unidos y Europa, representando un incremento del 41,6\% en comparación al ejercicio anterior. Si bien el volumen de exportación argentina también se ha incrementado en torno al 40\%, cabe destacar que se ha mantenido la diversificación de mercados y el desarrollo de nuevos clientes ${ }^{18}$.

\subsection{AFA}

El modelo organizativo de AFA combina la descentralización de la cooperativa en cada localidad y una administración centralizada que le permite acceder a las ventajas de la escala y a un relativo margen de autonomía local. Este original sistema de organización contribuye a la coordinación de los aspectos comerciales y de provisión de insumos, así como a la coordinación financiera de los 26 Centros Cooperativos Primarios, optimizando la utilización de estos recursos.

La función principal que tiene AFA es la colocación de los granos de los productores agropecuarios a través de los operadores de la Cooperativa tanto en el mercado interno como

18 ACA, Memoria y Balance correspondiente al ejercicio 2016-2017, Buenos Aires, 2017, p. 31. en el externo. En el caso del mercado local, a través de las Bolsas de Comercio de Rosario, de Buenos Aires y de Mercados a término. En el mercado internacional, lo hace a partir de la Bolsa de Cereales de Chicago y de la exportación directa a 61 países de Latinoamérica, América del Norte, Europa, Asia y África. Los objetivos primordiales del área de Comercialización son maximizar el valor de la producción que los socios venden a través de la Cooperativa y lograr un óptimo armado de la logística para la entrega de granos. Por otra parte, consigue el mejor precio del mercado para la producción acopiada, que es trasladado directamente a los productores asociados. Esta herramienta comercial es denominada Precio AFA y se ha convertido en uno de los símbolos que distinguen a AFA en el mercado agropecuario argentino.

En la actualidad, esta cooperativa se ha adaptado a las características del agronegocio y es funcional a éste. El gran crecimiento en su capacidad de almacenaje ocurre luego de la devaluación, ya que para 2002 ronda el millón y medio de toneladas. Si se tiene en cuenta que para el año 1982 su capacidad de acopio era de 500.000 toneladas, se infiere que a esta cooperativa le demandó veinte años sumar un millón de toneladas de capacidad adicional y solo ocho más agregar otro millón de toneladas.

El ejercicio económico cerrado el 31 de octubre de 2010 aporta otro dato revelador de lo redituable que le resulta a esta empresa el modelo impuesto en las últimas décadas en el agro argentino: durante ese año comercializa más de cuatro millones de toneladas de granos y alcanza una facturación bruta de $\$ 4.573$ millones. Para tener una idea de la magnitud de este volumen de negocios, puede comparárselo con el de ACA que factura en el mismo ejercicio $\$ 5.400$ millones, mientras que la multinacional Bunge y Born, en nuestro país tiene ingresos por $\$ 7.986$ millones $^{19}$.

Dentro de la singular estructura de AFA, el Centro Primario Cañada Rosquín ocupa en el último ejercicio (2016-2017) el quinto lugar en cuanto a su capacidad de almacenaje, después del de Las Rosas y Casilda (los tres en la provincia de Santa Fe) y de los de Rojas y Pergamino, ambos en la provincia de Buenos Aires. De las 213.157 toneladas que recepciona Cañada Rosquín, el subcentro de Charata aporta 56.560 toneladas (26,5\%). Por otra parte, el $57 \%$ del monto de operaciones realizadas por este CCP en el mismo ejercicio (2016-2017) corresponde a la comercialización de soja, confirmándose la transformación productiva que ha experimentado en las últimas décadas la provincia del Chaco, incorporada en la dinámica del agronegocio (ver Bageneta, 2015).

En cuanto a los subcentros que el CCP Maciel posee en el NOA (Metán y 7 de Abril) contribuyen con el 21.830 toneladas $(22,6 \%)$ de las 96.763 toneladas que el centro almacena para el mismo período. Del total de cereales y oleaginosas que comercializa este centro cooperativo primario en el año 2016-2017, el $72 \%$ corresponde a la soja. Otra evidencia de la centralidad que esta oleaginosa adquiere en este CCP que se expande con el cultivo de soja a provincias alejadas de su zona núcleo.

\footnotetext{
19 "AFA: un ícono del cooperativismo agrario pampeano", Infocampo, 11/02/2011. Disponible en https://www.infocampo.com.ar/afa-un-icono-del-cooperativismoagrario-pampeano/.
} 
Cuadro 2. Toneladas comercializadas por Agricultores Federados Argentino, 2012-2017

\begin{tabular}{|l|l|l|l|l|l|l|l|l|}
\hline Ejercicio & Totales en t & Trigo & Maíz & Girasol & \multicolumn{1}{c|}{ Sorgo } & Arveja & Soja & Varios \\
\hline $2012-13$ & 4.275 .833 & 375.311 & 1.139 .561 & 37.778 & 200.642 & 11.340 & 2.468 .998 & 42.203 \\
\hline $2013-14$ & 4.441 .027 & 389.268 & 951.259 & 19.240 & 141.711 & 18.263 & 2.898 .111 & 23.175 \\
\hline $2014-15$ & 5.728 .699 & 771.404 & 1.107 .167 & 26.267 & 115.978 & 20.959 & 3.674 .144 & 12.780 \\
\hline $2015-16$ & 4.788 .775 & 657.578 & 929.927 & 32.387 & 44.309 & 15.978 & 3.094 .897 & 13.699 \\
\hline $2016-17$ & 4.677 .257 & 849.558 & 924.976 & 36.975 & 72.576 & 19.532 & 2.760 .099 & 13.541 \\
\hline
\end{tabular}

Fuente: Agricultores Federados Argentinos, Memoria y Estados contables, 2016-2017, Rosario, 2017, p. 19

El Cuadro 2 revela la importancia de la soja en el volumen de cultivos comercializados por AFA en sus últimos ejercicios contables (años 2012-2017).

La incidencia que ocupa y mantiene la soja en el acopio y comercialización de AFA se ve reforzada a partir de 2012, cuando la cooperativa se convierte en una de las primeras entidades argentinas que comercializa poroto de soja sustentable según el esquema francés $2 B$ Svs $^{20}$. Los socios de AFA pueden ingresar en mercados más exigentes, que requieren estándares de sustentabilidad para la comercialización de biomasa o poroto de soja destinado a la fabricación de biocombustibles.

En la actualidad, AFA genera el acopio de unos 5 millones de toneladas anuales de cereales y oleaginosas, que representan aproximadamente el $6 \%$ de la producción nacional, y cuenta con una capacidad de almacenaje de 3 millones de toneladas. Asimismo, comercializa el $1 \%$ de la soja del mundo, convirtiéndose en la cooperativa de primer grado más grande de Sudamérica de acopio de granos.

Al igual que ACA, AFA a través de la Sección Agroinsumos provee a los productores rurales una variedad de insumos constitutivos de la lógica del agronegocio: semillas, plaguicidas y fertilizantes que revelan la supremacía de la soja. El glifosato es el herbicida de mayor uso y volumen operado, a pesar de sus cuestionamientos y mayor presencia de malezas resistentes que aparecen en la zona de influencia de AFA. El volumen total comercializado en el último ejercicio (2016-17) es de 6.992 .000 litros.

En consonancia con la política que implementa su gran competidor, ACA, de fomentar la diversificación de cultivos entre los productores asociados, AFA crea el Departamento de Productos Especiales. Se trata de un área destinada a acopiar, agregar valor, analizar mercados y comercializar producciones alternativas a las commodities tradicionales. Esos cultivos especiales son lentejas, arvejas, garbanzos, porotos, arroz, maíz pisingallo. Desde 2010 la Cooperativa incursiona en este rubro a partir de un proyecto iniciado en el CCP de J. B. Molina, que

\footnotetext{
20 Este esquema de certificación tiene dos requisitos básicos para la producción de poroto de soja a utilizar en la elaboración de biocombustibles sustentables: 1) Cambio directo de uso de suelo: el poroto de soja o biomasa debe provenir de campos que fueran agrícolas al 1/1/2008. 2) Cadena de custodia y trazabilidad: debe existir una trazabilidad, aunque sea documental, entre la biomasa proveniente del campo agrícola certificado y el biocombustibles distribuido en la Unión Europea. La certificación debe ser extendida y auditada en el campo donde el poroto de soja se cultiva, la planta de acopio, la aceitera y la planta de elaboración de biocombustibles.
}

en la actualidad permite que AFA sea uno de los referentes en el mercado local, además de convertirse en el principal exportador de arvejas, en especial a Brasil. A fines de 2013 comienza a funcionar una planta de procesamiento de legumbres en la localidad de Rueda, en el corazón de la zona legumbrera argentina.

A pesar de los difíciles momentos que pasa la ganadería en los últimos años, la cooperativa mantiene su pie en este segmento. Posee un feedlot con capacidad para engordar 1.500 animales y comercializa en el último ejercicio 72.499 cabezas por un monto de ventas en torno a $\$ 645.000 .000$. Las operaciones se hacen de manera directa, con el Mercado de Ganado de Rosario y en remates televisados. Por otra parte, por interés de su dirigencia, AFA adquiere el frigorífico Barrancas Coloradas, ubicado en la localidad entrerriana de Hernandarias.

AFA ya se había iniciado en el terreno de la industrialización, cuando en el año 1976, organiza en Las Rosas (provincia de Santa Fe) una metalurgia que hasta la actualidad se ocupa de fabricar los componentes necesarios para el adecuado funcionamiento y mantenimiento de las plantas de silos de sus 26 Centros Cooperativos Primarios. En 1993 comienza la industrialización de semillas oleaginosas. Para ello construye en la localidad santafesina de Los Cardos, una planta con capacidad de acopio de semilla de 120.000 toneladas y en la que trabajan más de 60 empleados. Toda la materia prima utilizada proviene de los socios. Actualmente la Aceitera Los Cardos industrializa bajo normas internacionales de calidad: aceite por solvente, harinas proteicas pelletizadas de soja, aceites de soja, girasol y colza y lecitina líquida, extracción de aceite por solvente, producción de harinas.

AFA brinda un conjunto de herramientas e instrumentos que posibilitan ahorros o beneficios económicos directos al productor en base a la participación, fidelidad y grado de cumplimiento operativo, en el marco de la política de Valor Agregado Cooperativo (VAC) hacia los asociados.

8. Eje: Ideas, auto-representación y legitimación social de las entidades

El capitalismo actual parecería que requiere de un sistema de justificación y legitimación que trascienda el mero objetivo 
de maximizar la ganancia. De allí que cuando el sistema capitalista debe responder y apaciguar la crítica para conservar la adhesión de sus tropas -que corren el peligro de prestar atención a las denuncias- procede a incorporar en su seno una parte de los valores en nombre de los cuales es criticado (ver Boltansky y Chiapello, 2002).

La pregunta por la construcción de legitimación social se encuadra en la concepción weberiana con sus cuatro formas organizativas: racional basada en fines u objetivos, racional basada en valores, afectiva y tradicional. En este caso, la legitimación deviene de la producción social de consenso. Los juicios legitimadores para Max Weber (2012) se sustentan en valores y remiten a la esfera subjetiva consensuada de un colectivo social.

La incorporación de nociones del paradigma del agronegocio, de valores e ideas que sustentan el capitalismo contemporáneo en comunidades locales, no siempre procede de modo lineal, automático, sino que se encuentra continuamente desafiado por los significados, valores y prácticas inherentes a las trayectorias de esas mismas comunidades.

El proyecto de poder, si bien es permanente nunca es definitivo y la agitación de las redes del agronegocio puede ser pensada como parte de la respuesta a la necesidad de una permanente reconstrucción de la hegemonía del sistema capitalista, donde el mercado es aquel espacio de circulación de los recursos y de los bienes pero no, la condición suficiente del funcionamiento de la economía: para que el mercado funcione se necesita cohesión social, gestión de conflictos, una ecología social pacificada y uniformada según un determinado modelo de pensamiento, un cosmos, en términos weberianos. Para ello se hace necesaria la regulación moral tanto de los pobres, como de los actores que encarnan y sostienen el desarrollo y profundización del modelo en los territorios (ver Córdoba, 2016).

8.1. ACA

Según Luisa Martín Rojo, todas las prácticas sociales son discursivas y como práctica social toda práctica discursiva tiene en cuenta las condiciones de producción, circulación e interpretación de un discurso. Por otra parte, los discursos forman sistemáticamente los objetos de los que hablan; como expresa Michel Foucault un discurso novedoso debe "definir aquello de que se habla, darle el estatuto de objeto y así hacerlo aparecer, volverlo nominable y descriptible" (ver Foucault, 1985). Asimismo, "los discursos no reflejan la realidad, no son un espejo fiel de ésta, sino que la construyen, mantienen, refuerzan interpretaciones de esa realidad; es decir, construyen representaciones de la sociedad, de las prácticas sociales, de los actores sociales y de las relaciones que entre ellos se establecen: generan un saber, un conocimiento" (ver Martín Rojo, 1977).

La lectura de las Memorias y balances de ACA, como del periódico La Cooperación y de la Revista Acaecer, muestra que su discurso no muestra tensiones entre el modelo cooperativo y el paradigma del agronegocio que aparece absolutamente naturalizado.

El imaginario institucional de ACA confirma su rol de expansión y de sustentabilidad del negocio agropecuario, en su triple naturaleza: económica, social y ambiental. El componente que marca su construcción identitaria es la prestación profesional de servicios, en primer lugar a las cooperativas primarias para que articulen una gestión organizativa de tipo racionalempresarial. Los servicios eficientes deben trasladarse al productor agropecuario (socio y no socio) y a los otros actores de la cadena agroindustrial.

Entre sus fortalezas destaca no solo la infraestructura tangible que incluye plantas de acopio, instalaciones portuarias, plantas industriales y oficinas administrativas, sino su infraestructura intangible, que es la credibilidad que mantiene después de 96 años.

8.2. AFA

Cualquier tipo de discurso presume exclusiones y obstáculos, delimita identidades y se construye como un proceso de la actividad social por la que se transmiten determinados saberes mediante la palabra y la simbolización. Las formaciones discursivas especifican quién puede hablar, de qué y cómo, pues los discursos construyen las posiciones de enunciación que habilitan a hablar de algunas cosas y no de otras (ver Balsa, 2006).

En el caso de AFA el discurso se muestra heredero de los visionarios y pioneros que fundan la institución que hoy es un referente en el mercado nacional de granos, ocupando el segundo lugar después de ACA. El 10\% de los productores del país, en su mayoría pequeños y medianos, son socios de la cooperativa, dándole origen y sustento. “... sin ellos no existiría AFA, como también sabemos que sin AFA, muchos de ellos hoy tampoco serían productores agropecuarios"21.

Al igual que en el caso de ACA, sus Memorias y balances y la revista Agricultores muestran un discurso institucional que en ningún momento cuestiona el agronegocio ni sus efectos ambientales. En el marco de la conmemoración de sus 80 años, se argumenta que en el origen de AFA está la preferencia por los productores de pequeñas y medianas dimensiones, aunque ello no significa una antinomia con los productores de grandes dimensiones económicas, sino una oportunidad e igualdad de trato para la consolidación y desarrollo de la agricultura familiar ${ }^{22}$.

\footnotetext{
21 Revista Agricultores, enero 2013, p. 41.

22 Ibid., p. 43
} 


\section{Algunas reflexiones finales}

El recorrido a través de estas dos entidades cooperativas agrarias ha permitido, a partir de los ejes seleccionados, dar cuenta de continuidades y rupturas, así como de similitudes y diferencias entre estas instituciones que además de compartir buena parte de su inserción territorial, propician la construcción de redes y están en relación directa con el agronegocio.

Ese mecanismo de construcción de redes es la tecnología de poder utilizada por el agronegocio en su búsqueda de legitimarse socialmente como el mejor modelo productivo posible. La red permite la construcción de un nosotros más amplio, que apunta a integrar a la población en un marco común de sentidos. En los términos de los actores del agro, la incorporación a una red garantiza un mayor acceso a recursos y por ende una mayor competitividad en el marco de las relaciones horizontales (ver Córdoba, 2016).

Más allá de las semejanzas, una diferencia a destacar entre ACA y AFA es su jerarquía, mientras la primera es una entidad de segundo grado, la segunda es una cooperativa primaria. Por lo tanto poseen distintas estructuras organizativas, aunque su entramado territorial se concentra en la región pampeana, con algunas expansiones que ambas han hecho hacia el NOA y el NEA.

La diferencia de escala también se advierte en la cantidad de asociados de cada una, mientras ACA nuclea a 50.000 socios, la entidad santafecina tiene 36.000 .

Las dos asociaciones tienen un rasgo común, vinculado con su capacidad para encaminar sus estructuras productivas hacia las características que demanda el agronegocio. Esta decisión y potencial de adaptación constituye una diferencia frente al gran número de cooperativas que desaparecieron ante las consecuencias de las políticas neoliberales en las áreas rurales.

En el plano discursivo, se reconoce el común intento de afianzarse en la práctica del agronegocio, referenciando la presencia de los pequeños y medianos agricultores, a quienes en gran medida las cooperativas han resguardado.

AFA participa de la concepción de Federación Agraria, que concibe al cooperativismo de manera integral y, por tanto, debe convertirse también en una escuela de aprendizaje gremial. En cambio, ACA, aunque con un evidente discurso y análisis político, no reconoce en su origen la función gremial y otorga a la acción cooperativa su tradicional función económica y social.

En las últimas décadas los distintos tipos de organizaciones asumen una mayor variedad de funciones en un contexto de complejidad ${ }^{23}$ también creciente. Entre otros rasgos centrales aumenta la ya estrecha interrelación del sistema económico mundial, convirtiendo en contexto de buena parte de las

\footnotetext{
23 Edgard Morin caracteriza a la sociedad actual como una sociedad compleja, en la que se relacionan permanentemente el orden y el desorden, ante lo cual la mejor estrategia para comprender y sobrevivir es asumir el caos de la cotidianeidad (ver Morin, 2013).
}

entidades a la mayoría de las variables básicas de la economía mundial. A su vez, el cambio tecnológico modifica aspectos básicos de los procesos de producción, distribución, comercialización y administración. En este escenario, ACA y AFA se transforman en organizaciones que tienden a minimizar las diferencias entre las cooperativas y las empresas de capital a los efectos de responder con mayor eficacia a los desafíos del nuevo contexto competitivo. Asimismo, introducen un nuevo lenguaje y enfoques diferentes para definir el papel del sector agropecuario en la economía nacional, que puede observarse mediatizado en un discurso tecnologizante centrado en la consideración de que el avance tecnológico y el conocimiento constituyen elementos vitales para la nueva ruralidad.

Fuentes y bibliografía

Asociación de Cooperativas Argentinas. Memorias y Balances, 1950-1951 y 2016-2017.

La Cooperación, diciembre 2017- julio 2018.

Recursos web: http://www.acacoop.com.ar/index.html

Agricultores Federados Argentinos. Sociedad Cooperativa Limitada. Balance Social Cooperativo, números 1 al 9. Ejercicios 2004/2005 a 2016/2017.

Agricultores Federados Argentinos. Sociedad Cooperativa Limitada. Memoria y Estados contables. Ejercicio económico n`81, 2012/2013, Ejercicio económico n 85, 2016/2017.

Agricultores Federados Argentinos. Sociedad Cooperativa Limitada. (2007). Surgimiento, desarrollo y organización chacarera en la historia de una cooperativa. Tomo I. Rosario.

Revista Agricultores, enero a diciembre, 2013. Diciembre 2017- julio 2018. Recursos web: http://www.afascl.com/

ANDRADE DE PAULA, D. y ANDRADE DE PAULA, E. (2007): "Agronegocio y Ambientalismo: reconstruyendo hegemonía", en GIRBAL-BLACHA, N.y REGINA DE MENDOÇA, S. (coords.), Cuestiones agrarias en Argentinay Brasil. Conflictos sociales, educación y medio ambiente, Buenos Aires, Prometeo.

BAGENETA, J. M. y MATEO, G. (2015): “Cooperativismo agrario y agronegocio. Tensiones entre un modelo centenario y los requerimientos de un agro reconvertido (1990-2010)". Disponible en http://www.cehsegreti. org.ar/historia-social-5/mesas\%20ponencias/MESA\%2010/BAGENETA-MATEO_10.pdf

BAGENETA, J. M. (2015): Del algodón a la soja. Territorio, actores y cooperativas en el Gran Chaco Argentino (1960-2010), Buenos Aires, InterCoop.

BARBERO, A.; GORENSTEIN, S. y GUTIÉRREZ, R. (2000): El impacto de los cambios institucionales en el cooperativismo agropecuario pampeano, Bogotá, Pontificia Universidad Javeriana.

BARSKY, O. y GELMAN, J. (2001): Historia del agro argentino. Desde la conquista hasta fines del siglo XX, Buenos Aires, Mondadori.

BLANCO, M. (2005): "Argentina: la incorporación de la agricultura conservacionista en la región pampeana" Debate agrario: Análisis y Alternativas, 38, Centro Peruano de Estudios Sociales - CEPES. 
BOLSI, A. (2008): "El norte argentino entre las persistencias y los cambios", en BALSA, J.; MATEO, G. y OSPITAL, M. S. (comps.), Pasado y Presente en el agro argentino, Buenos Aires, Lumiere.

BOLTANSKY, L. y CHIAPELLO, E. ((2002): El nuevo espíritu del capitalismo, Madrid, Akal.

BOZZANO, H. (2017): Territorios posibles. Procesos, lugares y actores, Buenos Aires, Lumiere.

CÓRDOBA, M. S. (2016): Viaje al corazón del negocio agrícola. Dispositivos de legitimación e intervención territorial del modelo de agronegocios en Argentina, Buenos Aires, UNSAM.

EL LITORAL: https://www.ellitoral.com/

FONTENLA, E. (2015): Cooperativas Agropecuarias Argentinas. Nueva Generación de Cooperativas, Colegio de Graduados en Cooperativismo y Mutualismo de la República Argentina (CGCyM). Disponible en http:// cgcym.org.ar/wp-content/uploads/2015/06/Cooperativas-Agropecuarias-Argentinas_Fontenla.pdf

FOUCAULT, M. (1985): Las palabras y las cosas, Buenos Aires, Planeta-Agostini.

GIRBAL-BLACHA, N. (2013): "El poder de la tierra en la Argentina. De la cultura agrícola al agronegocio", Estudios Rurales, 4, CEAR-UNQ.

GIRBAL-BLACHA, N. y MATEO, G. (2014): "El agro argentino: de granero del mundo a país sojero", en LOZANO, M. y FLORES, J. (coords.), Democracia y sociedad en la Argentina contemporánea, Reflexiones sobre tres décadas, Bernal, UNQ.

INFOCAMPO: https://www.infocampo.com.ar/

LA NACIÓN: https://www.lanacion.com.ar/

LATTUADA, M. (2006): Acción Colectiva y corporaciones agrarias en la Argentina. Transformaciones institucionales a los fines del siglo XX, Bernal, UNQ.

LATTUADA, M. y RENOLD, J. M. (2004): El cooperativismo agrario ante la globalización, Buenos Aires, Editorial Siglo XXI.

MANÇANO FERNANDES, B. (2004): Movimientos Socioterritoriales y Movimientos Socioespaciales. Contribución teórica para una lectura geográfica de los Movimientos Sociales. Disponible en http://web.ua.es/ en/giecryal/documentos/documentos839/docs/bmfunesp-5.pdf

MANÇANO FERNANDES, B. (2009): “Territorios, teoría y política”, en CALDERÓN, G. y LEÓN, E. (coords.) Descubriendo la espacialidad social en América Latina, vol. 3, México, Editorial Itaca.

MARTín ROJO, L. (1997): "El orden social de los discursos" Discurso, 21-22, México.

MARTÍNEZ DOUGNAC, G. (coord.) (2013): De especie exótica a monocultivo, Estudios sobre la expansión del cultivo de soja en Argentina, Buenos Aires, Imago Mundi.

MARTÍNEZ DOUGNAC, G. (2016): Monocultivo sojero, concentración económica, acaparamiento y despojo de tierras. Formas actuales de la expansión del capital en la agricultura argentina, Buenos Aires, Legem Ediciones.

MATEO, G. (2005): "El corporativismo rural frente a la política agraria peronista: SRA - FAA - ACA" en GALAFASSI, G. y LÁZZARO, S. (coords.), Sujetos, políticas públicas y representaciones del mundo rural. Argentina 1930-1976, Buenos Aires, Siglo Veintiuno de Argentina Editores.

MATEO, G. (2006): “Un clásico del cooperativismo agrario argentino: la Asociación de Cooperativas Argentinas, primera cooperativa de cooperativas", en GRACIANO, O. y GUTIÉRREZ, T. (coords.), El agro en cuestión. Discursos, políticas y corporaciones en la Argentina, 1870-2000, Buenos Aires, Prometeo.

MATEO, G. y OLIVERA, G. (2006): “Corporaciones agrarias y cooperativismo en la Argentina peronista (1946-1955). Un estudio comparativo entre la Federación Agraria Argentina (FAA) y la Asociación de Cooperativas Argentinas (ACA)", en OLIVERA, G. (comp.), Cooperativismo Agrario: Instituciones, Políticas Públicas y Procesos Históricos, Córdoba, Ferreira Editor.
MATEO, G. (2012): Cooperativas agrarias y peronismo. Acuerdos y discrepancias. La Asociación de Cooperativas Argentinas, Buenos Aires, CICCUS.

MORIN, E. (2013): Introducción al pensamiento complejo, Barcelona, Gedisa.

NUN, J. (1987): "La teoría política y la transición democrática" en NUN, J. y PORTANTIERO, J. C. (comps.), Ensayos sobre la transición democrática en Argentina, Buenos Aires.

ORDOÑEZ, H. (2009): La nueva economía y negocios agroalimentarios, Buenos Aires, Editorial Facultad de Agronomía.

PORTO-GONÇALVES, C. (2008): "De saberes e de territórios: diversidade e emancipaçao a partir de experiencia latinoamericana" en CECEÑA, A. (coord.), De los saberes de la emancipación y de la dominación, Buenos Aires, CLACSO. Disponible en http://biblioteca.clacso.edu.ar/ $\mathrm{gsdl} / \mathrm{collect} / \mathrm{clacso} / \mathrm{index} / \mathrm{assoc} / \mathrm{D} 1765$.dir/saberes.pdf

ROBIN, M. (2008): El mundo según Monsanto, Madrid, Editorial Península.

SANTACOLOMA, P.; SUÁREZ, R. y RIVERO, H. (2005): Fortalecimiento de los vínculos de agronegocios con los pequeños agricultores. Estudios de caso en América Latina y el Caribe, Roma, Organización de las Naciones Unidas para la Agricultura y la Alimentación.

SANTOS, M. (1996): La naturaleza del espacio. Técnica y tiempo. Razón y emoción, Barcelona, Ariel.

VOLANTE, J. et al (2006): Análisis de la dinámica del uso del suelo del Noroeste Argentino mediante teledetección y SIG, Salta, INTA. Disponible en Http://www.inta.gov.ar/prorenoa/zonadescarga/uso_suelo/ Analisis_de_la_dinamica_del_uso_del_suelo.pdf;

VIGLIZZO, E. y JOBBÁGY, E. (eds.) (2010): Expansión de la frontera agropecuaria en Argentina y su impacto ecológico-ambiental, INTA. Disponible en: https://inta.gob.ar/documentos/expansion-de-la-fronteraagropecuaria-en-argentina-y-su-impacto-ecologico-ambiental.

WEBER, M (2012): Economía y Sociedad, Buenos Aires, FCE.

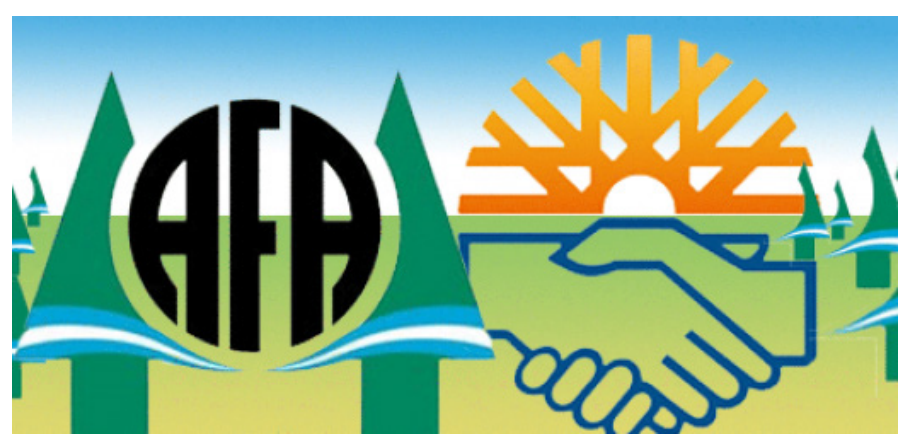

